\title{
Dietary Modulation of Active Potassium Secretion in the Cortical Collecting Tubule of Adrenalectomized Rabbits
}

\author{
Charles S. Wingo, Donald W. Seldin, Juha P. Kokko, and \\ Harry R. JaCobson, University of Texas Health Science Center, at Dallas, \\ Southwestern Medical School, Dallas, Texas 75235
}

A B S T R A C T Addisonian patients can maintain potassium homeostasis despite the absence of mineralocorticoid. The present in vitro microperfusion studies examine what role the cortical collecting tubule might play in this process. All studies were performed on tubules harvested from adrenalectomized rabbits, which were maintained on $0.15 \mathrm{M} \mathrm{NaCl}$ drinking water and dexamethasone $50 \mu \mathrm{g} / \mathrm{d}$. Perfusion and bath solutions were symmetrical Ringer's bicarbonate with [K] of $5 \mathrm{meq} /$ liter. Initial studies on cortical collecting tubules from adrenalectomized animals ingesting a high potassium chow ( 9 meq $\mathrm{K} / \mathrm{kg}$ body wt) demonstrated net potassium secretion against an electrochemical gradient (mean collected fluid [K] 16.5 \pm 2.6 $\mathrm{meq} /$ liter with an observed transepithelial voltage of $-6.3 \pm 4.1 \mathrm{mV}$; predicted voltage for passive distribution of potassium being $-28.2 \mathrm{mV}$ ). To examine whether this active potassium secretion could be modulated by dietary potassium, independent of mineralocorticoid, two diets identical in all respects except for potassium content were formulated. Potassium secretion was compared in cortical collecting tubules harvested from adrenalectomized animals on low $(0.1$ meq $\mathrm{K}$ ) and high (10 meq $\mathrm{K}$ ) potassium intake.

Mean net potassium secretion by cortical collecting tubules was $2.02 \pm 0.54$ peq $\mathrm{mm}^{-1} \mathrm{~min}^{-1}$ in the low potassium diet group and $5.34 \pm .74 \mathrm{peq} \cdot \mathrm{mm}^{-1} \cdot \mathrm{min}^{-1}$ in the high potassium group. The mean transepithelial voltages of the collecting tubules did not differ between the two dietary groups. While net $\mathrm{Na}$ reabsorption was significantly greater in tubules from the high $\mathrm{K}$ group, this could not account for the differences in $\mathrm{K}$ secretion. These data demonstrate that: $(a)$ the cortical collecting tubule can actively secrete potassium and that the magnitude of this potassium secretion correlates with potassium intake; $(b)$ this active

Received for publication 10 December 1981 and in revised form 30 April 1982. potassium secretory process is independent of mineralocorticoid. These findings support the hypothesis that the cortical collecting tubule may contribute to $\mathrm{K}$ homeostasis in Addison's disease.

\section{INTRODUCTION}

Administration of mineralocorticoids produces a kaliuresis when sodium intake is not restricted $(1,2)$. Similarly, disease states associated with excess endogenous adrenocortical steroids are associated with large amounts of potassium in the urine and hypokalemia. In contrast, selective mineralocorticoid deficiency and generalized adrenocortical-deficient states such as Addison's disease frequently result in some degree of hyperkalemia. However, although mild hyperkalemia is common in the Addisonian, severe hyperkalemia is rare in the absence of cardiovascular collapse (3). Moreover, potassium homeostasis is preserved in adrenocortical insufficiency, as judged by stable serum potassium levels, and renal potassium excretion, which appears comparable to normal $(4,5)$.

These findings suggest that the kidney is capable of regulating potassium excretion independent of mineralocorticoids. The following statements are generally accepted: (a) Renal potassium excretion is the principle determinant of potassium homeostasis when glomerular filtration rate is not significantly less than normal (6); (b) Renal potassium excretion is primarily determined by distal nephron potassium secretion $(7,8)$; (c) A significant portion of distal potassium secretion occurs in the cortical collecting tubule $(9) ;(d)$ The cortical collecting tubule is a target epithelium for mineralocorticoids (9-11); (e) Potassium secretory flux measured in vitro in this segment is increased by increasing in vivo mineralocorticoid levels chronically $(12-14) ;(f)$ Active potassium secretion has been demonstrated in the cortical collecting tubule of normal rabbits (15-17). In view of these preceding observations, we wished to determine first, whether potassium 
secretion occurs in this nephron segment in the absence of mineralocorticoid; second, whether this potassium secretion is an active process; third, if a mineralocorticoid independent potassium secretory process is present, is it responsive to dietary potassium intake; and fourth, to determine what factors, independent of mineralocorticoid, may modulate potassium secretion.

\section{METHODS}

Two groups of experiments were conducted. In both, female New Zealand White rabbits that weighed between 1 and 2 $\mathrm{kg}$ were used. These animals underwent bilateral adrenalectomy at least 7 (protocol I) or 14 (protocol II) d before experimentation and were maintained on $0.15 \mathrm{M}$ sodium chloride drinking water and $50 \mu \mathrm{g} / \mathrm{d}$ dexamethasone until experimentation. Care was taken at time of adrenalectomy to search for ectopic adrenal tissue and remove it when such was found. This occurred infrequently and in no animal in our study.

In the first group of experiments (protocol I) rabbits were fed a high potassium diet (Wayne $15 \%$ rabbit ration, Allied Mills, Inc., Chicago, IL, $351 \mathrm{meq} \mathrm{K} / \mathrm{kg}$ diet). The measured consumption of this diet was $25-30 \mathrm{~g} / \mathrm{kg}$ rabbit body weight for an average potassium ingestion of $9.3 \mathrm{meq} / \mathrm{kg}$ per $\mathrm{d}$. Animals consumed this diet for at least $4 \mathrm{~d}$ before and $7 \mathrm{~d}$ after adrenalectomy. At the time of experimentation arterial ear blood was obtained for plasma sodium and potassium. Aldosterone and corticosterone levels were measured from blood from the transected neck. (These were performed as radioimmunoassays by Dr. William Campbell, Department of Clinical Pharmacology, University of Texas Health Science Center, Dallas).

In the second group of experiments (protocol II) rabbits were fed one of three synthetic diets containing low, normal, and high amounts of potassium (diets prepared by ICN Nutritional Biochemicals, Cleveland, $\mathrm{OH}$ ). The electrolyte composition of the diets is shown in Table I. All diets had essentially identical amounts of sodium, calcium, phosphorus, and magnesium. All rabbits were fed the normal potassium diet for $7 \mathrm{~d}$ before adrenalectomy. No tubules were studied from rabbits on the normal potassium diet. The 7-d preadrenalectomy period had two purposes: $(a)$ to have the rabbits enter the study with similar dietary backgrounds; (b) to allow the rabbits time for adjusting to the taste and consistency of the synthetic diet. We learned that without such a preadrenalectomy exposure to the synthetic diet some rabbits would not eat well in the postoperative period. After surgery

TABLE I

Electrolyte Composition of Synthetic Potassium Diet for Protocol II

\begin{tabular}{lrcr}
\hline & Low K & Normal K & High K \\
\hline & & $m m o l / 100$ g diet \\
$\mathrm{K}$ & 0.31 & 3.41 & 30.11 \\
$\mathrm{Na}$ & 5.25 & 5.30 & 5.28 \\
$\mathrm{Ca}$ & 13.31 & 12.28 & 12.11 \\
$\mathrm{PO}_{4}$ & 8.85 & 7.78 & 8.89 \\
$\mathrm{Mg}$ & 1.96 & 1.95 & 2.08 \\
$\mathrm{Cl}$ & 1.00 & 1.30 & 25.33 \\
\hline
\end{tabular}

the animals were divided into two groups that were treated identically except for the diet they were fed. Rabbits were housed in metabolic cages and food consumption and urine output were quantified. Rabbits on the low potassium diet had an average intake of $32 \mathrm{~g} / \mathrm{d}$ of the low potassium feed for an average potassium ingestion of $0.10 \mathrm{meq} / \mathrm{d}$, whereas the average intake on the high potassium diet was $34 \mathrm{~g} / \mathrm{d}$ for an average potassium ingestion of $10.2 \mathrm{meq} / \mathrm{d}$. Potassium determinations were made on a 24-h urine collection obtained the day before experimentation and on arterial ear blood, muscle, and kidney cortex at the time of sacrifice. Urine and blood [K] were measured using standard flame photometry. Muscle and kidney $\mathrm{K}$ content were measured as described by Knochel and Schlein (18) and expressed as milliequivalent per $100 \mathrm{~g}$ fat-free dry solids. Arterial $\mathrm{pH}$ was also measured using a Corning $\mathrm{pH} /$ blood gas machine (model 165, Corning Medical, Corning Glass Works, Medifield, MA). Plasma mineralocorticoid levels were determined as previously described using plasma obtained at death.

Segments of rabbit cortical collecting tubules were isolated and perfused in vitro as originally described by Burg et al. (19). Briefly, rabbits were decapitated, one kidney quickly removed, and 1-2-mm thick coronal slices were placed in a chilled petri dish containing an artificial ultrafiltrate of plasma. Concentrations in millimolar were sodium 145 , potassium 5, chloride $112, \mathrm{HCO}_{3} 25$, calcium $1.8, \mathrm{PO}_{4} 2.3, \mathrm{Mg}$ $1.0, \mathrm{SO}_{4} 1.0$, acetate 10 , glucose 8 , and alanine 5 . The dissection, bath, and perfusion solutions were identical except that to both the dissection and bath solutions $1-5 \% \mathrm{vol} / \mathrm{vol}$ fetal calf solution was added. Results using varying amounts of fetal calf serum did not differ and were thus pooled. The perfusate contained $50 \mu \mathrm{Ci} \mathrm{ml} l^{-1}$ of [methoxy $-{ }^{3} \mathrm{H}$ ] inulin, exhaustively dialyzed according to Schafer et al. (20). All solutions were gassed to $\mathrm{pH} 7.4$ with a $95 \% \mathrm{O}_{2}, 5 \% \mathrm{CO}_{2}$ mixture.

Care was taken to start dissection at the corticomedullary junction and to continue dissection superficially until a branch point was identified. Tubules were cut just distal to the branch point and just proximal to the corticomedullary junction and were transferred to a thermostatically controlled perfusion chamber. The two ends of the tubule segment were sucked into holding pipettes and sealed into place by an elastomeric silicone resin, Sylgard 184 (Dow Corning Corp., Midland, MI), which had been placed into the tips of the holding pipettes. The perfusion pipette, which had been centered in one of the holding pipettes, was advanced $\sim 100-200 \mu \mathrm{m}$ beyond the holding pipette and the tubule perfused between $1-3 \mathrm{nl} \min ^{-1}$ by adjusting the height of a water column attached to the rear of the perfusion pipette. This pipette also served as an intraluminal electrode because it was connected, via a Ringer's bicarbonate-agarose bridge, to a calomel electrode. To complete the electrical circuit and allow measurement of transepithelial voltage $\left(V_{T}\right)$, the bath fluid in the perfusion chamber was also connected to a calomel electrode via an identical agarose bridge. The circuit used to measure transepithelial voltage has been diagrammed (21). It was possible in all tubules to distinguish the superficial and juxtamedullary ends of the tubule, and in all but five experiments (three in protocol $I$ and two in protocol II) it was possible to perfuse the tubules in an antegrade manner. All tubules were perfused at $37 \pm 0.5^{\circ} \mathrm{C}$ and were allowed to equilibrate for at least $60 \mathrm{~min}$. Perfusate which had coursed through the tubules was collected under water-equilibrated mineral oil and sampled at time intervals using a constant volume pipette. Bath fluid continuously flowed through the perfusion chamber at $0.64 \mathrm{~cm}^{3} \mathrm{~min}^{-1}$.

Volume reabsorption was measured by timed collections 
of perfused fluid via a constant volume pipette, and was calculated as $\mathrm{J}_{\mathrm{v}}=\left(\mathrm{cpm}_{0} / \mathrm{cpm}_{\mathrm{i}}-1\right) \mathrm{V}_{0} / \mathrm{L}$ where $\mathrm{J}_{\mathrm{v}}$ equals net

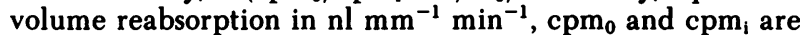
the $\left[{ }^{3} \mathrm{H}\right]$ inulin counts per minute in the collected and perfused fluid, respectively, $V_{0}$ is the collected fluid flow rate, and $L$ is the perfused tubule length. In all experiments [ $\left.J_{v}\right]$ was $<0.05 \mathrm{nl} \mathrm{mm}^{-1} \mathrm{~min}^{-1}$.

Three to six timed samples for net potassium and sodium flux measurements were obtained, using a calibrated constant volume pipette. The contents of this pipette were quantitatively transferred to a diluent cuvette into which a precisely measured amount of diluent containing $30 \mathrm{mM} \mathrm{CsNO}_{3}$ (density grade, Gallard-Sclesinger Chemical Mfg. Corp., Carle Place, NY) and $5 \mathrm{mM} \mathrm{NH} \mathrm{NH}_{2} \mathrm{PO}_{4}$ had been placed under water-equilibrated mineral oil. Sample determinations were made using a Helium glow photometer (Aminco, Silver Springs, MD). Each sample was run at least in triplicate. Perfusate [K] was also measured by helium glow photometry. Again, at least three samples of perfusate were run at least in triplicate. Net potassium flux, $\mathrm{J}_{\mathbf{K}}$ in pmoles $\mathrm{mm}^{-1}$ $\min ^{-1}$ was calculated as follows: $J_{K}=\left([K]_{1}-[K]_{0}\right) V_{0} / L$ where $[K]_{i}$ and $[K]_{0}$ are concentrations of potassium in the perfused and effluent fluid, $V_{i}$ is perfusion rate, and $V_{0}$ and $L$ are as defined before. Sodium flux was calculated in a similar manner. The response of the helium-glow photometer was linear throughout a $1,200-\mathrm{mV}$ range for $\mathrm{Na}(0-150 \mathrm{mM})$ and a 1,000-mV range for $\mathrm{K}(0-25 \mathrm{mM})$. Respective slopes for $\mathrm{Na}$ and $K$ were $8 \mathrm{mV} / \mathrm{mM} \mathrm{Na}$ and $40 \mathrm{mV} / \mathrm{mM} \mathrm{K}$. The mean variation in identical samples (perfusates) was within $3 \%$.

Statistical analyses were performed using Student's $t$ test or linear regression model, as appropriate. The null hypothesis was rejected at a 0.05 -level of significance.

\section{RESULTS}

Plasma measurements-protocol I. Table II lists the plasma sodium, potassium, and aldosterone levels in the rabbits. All animals were slightly hyponatremic with a mean plasma [Na] of $129 \mathrm{mM}$. In addition, although all animals were hyperkalemic, the highest
TABLE II

Rabbit Plasma Measurements

\begin{tabular}{cccc}
\hline Experiment & $\mathrm{Na}$ & $\mathrm{K}$ & Aldosterone \\
\hline & meq/liter & meq/liter & $n g /$ dl \\
1 & 126 & 6.1 & $\mathrm{ND}$ ! \\
2 & 128 & 6.1 & $\mathrm{ND}$ \\
3 & 129 & 5.5 & $\mathrm{ND}$ \\
4 & 131 & 5.1 & 4 \\
5 & 131 & 5.1 & ND \\
6 & 127 & 5.3 & 1 \\
7 & 129 & 5.3 & ND \\
8 & 131 & 5.1 & ND \\
9 & 132 & 6.3 & ND \\
Mean \pm SEM & $129 \pm .69$ & $5.5 \pm .16$ & ND \\
\hline
\end{tabular}

- Normal values for this assay $>15 \mathrm{ng} / \mathrm{dl}$.

$\downarrow$ ND $=$ Not detectable.

plasma potassium was $6.3 \mathrm{mM}$ with a mean [K] of 5.5 $\mathrm{mM}$. Plasma aldosterone levels were undetectable in all but two animals and in these two it was well below the normal range. All of these animals had undetectable plasma corticosterone levels. Plasma from normal animals, obtained at the same time and treated in an identical manner was submitted for analysis in a blinded manner to Dr. William Campbell's laboratory. The mean plasma corticosterone level in five normal rabbits was $2,034 \pm 681$ (SD) $\mathrm{mg} / \mathrm{dl}$. Plasma corticosterone levels were also determined for the animals in protocol II. None had detectable corticosterone levels. The data provide good evidence for adequacy of adrenalectomy in these animals.

Microperfusion potassium flux data-protocol I. Listed in Table III are the results of the potassium flux

TABLE III

Results of Potassium Flux Studies in Cortical Collecting Tubules

\begin{tabular}{|c|c|c|c|c|c|}
\hline Experiment & {$[\mathbf{K}$ ]in } & [K]out & K Flux & v:T $_{\mathbf{T}}^{\mathbf{q}} \mathbf{t}$ & $V_{T}^{\text {obos }}$ \\
\hline & meq/liter & meq/liter & $\mathrm{peq} / \mathrm{mm} / \mathrm{min}$ & $m V$ & $m V$ \\
\hline 1 & 4.8 & 12.3 & $-6.4^{\circ}$ & -25.1 & -4.7 \\
\hline 2 & 4.0 & 7.6 & -2.8 & -17.1 & 2.3 \\
\hline 3 & 7.1 & 12.5 & -1.6 & -15.1 & 0.1 \\
\hline 4 & 5.5 & 14.1 & -3.8 & -25.1 & 8.0 \\
\hline 5 & 5.4 & 21.6 & -8.4 & -37.0 & -22.5 \\
\hline 6 & 6.4 & 16.6 & -5.3 & -25.5 & -13.5 \\
\hline 7 & 4.1 & 16.5 & -5.3 & -37.2 & -0.3 \\
\hline 8 & 5.8 & 34.1 & -9.8 & -47.3 & -27.8 \\
\hline 9 & 5.0 & 12.6 & -4.9 & -24.7 & 2.0 \\
\hline Mean士SEM & $5.3 \pm 0.3$ & $16.5 \pm 2.5$ & $-5.37 \pm .86$ & $-28.2 \pm 2.2$ & $-6.3 \pm 4.1$ \\
\hline
\end{tabular}

- Negative sign denotes net secretion.

† Calculated voltage required to account for $\mathrm{K}$ distribution on a wholly passive basis.

$\S$ Observed voltages. 
studies. This table lists the mean data for each tubule. In each experiment there is a rise in $[\mathrm{K}]$ of collected fluid over the $[\mathrm{K}]$ in the perfused fluid. Hence, there is net secretion of potassium denoted by $\mathrm{J}_{\mathrm{k}}<0$ in each experiment. When potassium secretion is plotted vs. the observed transepithelial voltage for each experimental period, Fig. 1, there is a correlation of these two variables with potassium secretion increasing with lumen negativity. There was net potassium secretion, however, even when the transepithelial voltage was lumen positive. Under this condition net potassium movement was against its electrochemical gradient.

In those instances in which the transepithelial voltage was negative it is necessary to consider whether the observed transepithelial voltage is sufficient to explain the observed rise in potassium concentration along the tubule. To evaluate this question we plotted in Fig. 2 the ratio of collected fluid to bath $\mathrm{K}$ concentration, $[\mathrm{K}]_{\text {out }} /[\mathrm{K}]_{\text {bath }}$ vs. transepithelial voltage. Again, as in Fig. 1, the data for individual collections are plotted. The solid line is that of diffusion equilibrium described by the Nernst equation. The points are the observed data from these nine experiments. We have plotted every individual collection period separately to demonstrate that each datum is displaced well above the Nernst equation. This shows that potassium is not simply distributed passively across the epithelium.

Estimates of the passive contribution to $\mathrm{K}$ flux by three different methods are provided in Table IV. The largest estimate of passive flux (26\% of total observed net $K$ secretion) was obtained using the difference between lumen and bath $K$ concentrations predicted by the Nernst equation. Using the Goldman equation:

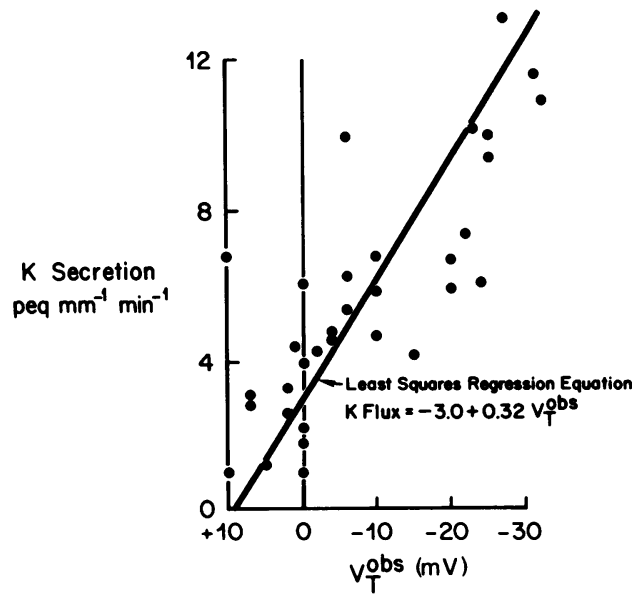

Figure 1 Net K secretion in cortical collecting tubules from adrenalectomized rabbits in protocol $I$ is plotted against the observed transepithelial voltage ( $\left.\mathrm{V}_{\mathrm{T}} \mathrm{Obs}\right)$. A highly significant relationship is observed with $\mathrm{K}$ secretion increasing as $\mathrm{V}_{\mathrm{T}}$ obs is more negative. $r=0.80$.

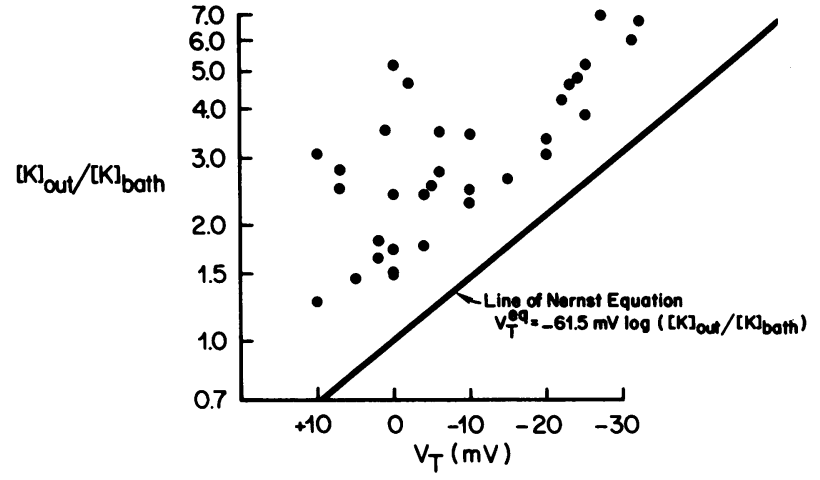

Figure 2 Plotted in this figure is the ratio of $\mathrm{K}$ concentrations in collected fluid ([K] out $)$ and bath fluid $\left([\mathbf{K}]_{\text {bath }}\right)$ against the observed transepithelial voltage. Data are from cortical collecting tubules from adrenalectomized rabbits in protocol I. All $[\mathrm{K}]_{\text {out }} /[\mathrm{K}]_{\text {bath }}$ fall above the solid black line, which represents the calculated relationship between $[K]_{\text {out }} /[\mathrm{K}]_{\text {bath }}$ and the transepithelial voltage using the Nernst equation. Each point represents a single collection period.

$$
\mathrm{J}_{\mathrm{K}}=\frac{\mathrm{zF}}{\mathrm{RT}} \cdot \mathrm{P} \cdot \mathrm{V}_{\mathrm{T}} \cdot \frac{[\mathrm{K}]_{1}-\left[\mathrm{K}_{\mathbf{b}} \cdot \mathrm{e}^{-\mathrm{V}_{\mathrm{TZ}} \mathrm{F} / \mathrm{RT}}\right.}{1-\mathrm{e}^{-\mathrm{V}_{\mathrm{TZ}} \mathrm{F} / \mathrm{RT}}},
$$

where $\mathrm{z}, \mathrm{F}, \mathrm{R}, \mathrm{T}$ have their usual meaning and where $P$ refers to $K$ permeability, $V_{T}$ to observed voltage, and $[\mathrm{K}]_{\mathrm{l}}$ and $[\mathrm{K}]_{\mathrm{b}}$ to lumen and bath $\mathrm{K}$ concentrations, lower estimates of passive $\mathrm{K}$ secretion are obtained. In making these calculations, we used $\mathrm{K}$ permeability measurements from Stoner et al. (16) and Stokes (17). Cal-

TABLE IV

Comparisons of Observed Potassium Flux to Three Different Estimates of Passive Potassium Fluxes

\begin{tabular}{ccccc}
\hline & & \multicolumn{3}{c}{ Calculated K flux } \\
\cline { 3 - 5 } Experiment & $\begin{array}{c}\text { Observed K } \\
\text { flux }\end{array}$ & Nernst & Goldmant & Goldman $\$$ \\
\hline 1 & $-6.4^{\bullet}$ & -0.8 & -0.3 & 0.7 \\
2 & -2.8 & +0.3 & 0.1 & 0.7 \\
3 & -1.6 & 0.0 & 0.0 & 0.9 \\
4 & -3.8 & +0.6 & 0.6 & 2.1 \\
5 & -8.4 & -3.8 & -1.7 & -0.4 \\
6 & -5.3 & -2.8 & -1.2 & -0.2 \\
7 & -5.3 & -0.2 & -0 & 1.5 \\
8 & -9.8 & -3.9 & -2.3 & -0.5 \\
9 & -4.9 & -0.2 & +0.1 & 1.3 \\
& & & & \\
Mean \pm SEM & $-5.37 \pm 0.86$ & $-1.43 \pm 0.31$ & $-0.52 \pm 0.33$ & $0.68 \pm 0.29$ \\
\hline
\end{tabular}

- Negative sign denotes net secretion; positive values denote net reabsorption.

I Calculated $\mathrm{K}$ flux ignoring the [K] gradient that develops between lumen and bath.

\$ Calculated using the log mean concentration gradient between lumen and bath. 
culations were made both ignoring and taking into account the rise in luminal $\mathrm{K}$ concentration that occurs in net $\mathrm{K}$ secretion. It should be noted that the permeability coefficients used, $1-1.06 \times 10^{-5} \mathrm{~cm} \cdot \mathrm{s}^{-1}(16$, 17) were obtained using cortical collecting tubules from normal rabbits.

Our calculations are thus consistent with the notion that $\mathrm{K}$ transport in these cortical collecting tubules is not mainly attributable to passive, voltage induced $\mathrm{K}$ distribution. Accordingly, we label this $\mathrm{K}$ transport as active. In so doing, we use the general definition of active transport as a process in which the movement of an ion across an epithelium cannot be solely accounted for by the laws of simple ionic diffusion across single membranes.

Plasma and urine measurements-protocol II. The

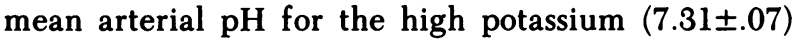
and low potassium (7.28 \pm .04$)$ group were not significantly different. Plasma potassium and urinary potassium excretion were greater in the high potassium dietary group than in the low potassium group (Fig. 3). Likewise, muscle and kidney cortex potassium content was greater in the high potassium group than in the low potassium group (Fig. 3).

Microperfusion data-protocol II. Eight cortical collecting tubules from high $\mathrm{K}$ rabbits and seven cortical collecting tubules from low $\mathrm{K}$ rabbits were studied. In most of the tubules ( 5 high $\mathrm{K}$ and 6 low $\mathrm{K}$ ) two sets of three collections for $\mathrm{Na}$ and $\mathrm{K}$ were obtained. One set was obtained $\sim 1-2 \mathrm{~h}$ after perfusion was initiated and another obtained about 3-4 h after initiation of perfusion. Early and late results were not significantly different. Comparison of the mean transepithelial voltage and potassium secretion are given in Fig. 4. The mean transepithelial voltages of cortical collecting tubules from rabbits on the high potassium and low potassium diets were not significantly different $(+2.1 \pm 1.3 \mathrm{mV}$ vs. $+2.6 \pm 2.3 \mathrm{mV}$, respectively). How-
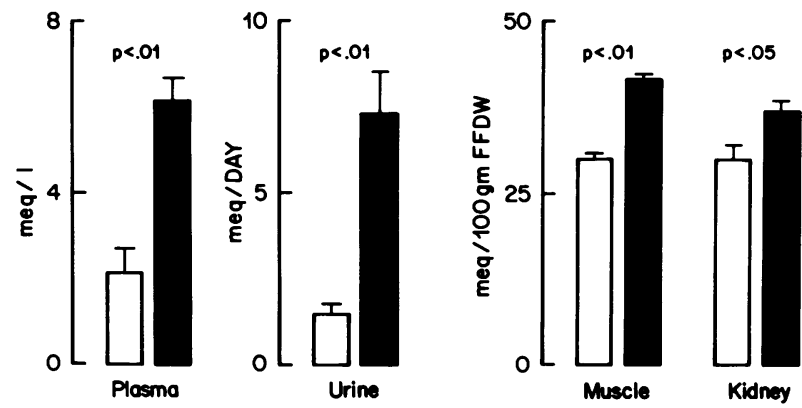

Figure 3 Plasma urine and tissue $K$ are plotted for adrenalectomized rabbits in protocol II. Data from animals on a low $\mathrm{K}$ diet are depicted by open bars and data from animals on a high $\mathrm{K}$ diet are depicted by solid bars.
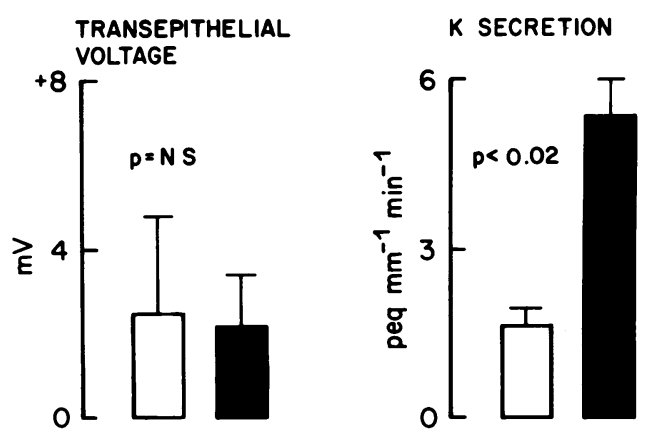

Figure 4 Plotted here are the mean transepithelial voltages and net $\mathbf{K}$ secretion in cortical collecting tubules from adrenalectomized rabbits in protocol II. Values for tubules obtained from animals on low $(n=7)$ and high $(n=8) \mathrm{K}$ diets are depicted in open and closed bars, respectively.

ever, potassium secretion by tubules from the high potassium diet group was more than twice that of the low potassium group $(2.02 \pm 0.54$ vs. $5.34 \pm 0.74$ peq $\left.\mathrm{mm}^{-1} \mathrm{~min}^{-1}\right)$. This difference is significant. However, examination of the mean group differences obscures the effect of transepithelial voltage on potassium secretion. As shown in Fig. 5, both groups of tubules demonstrated a significant relation between voltage and $\mathrm{K}$ secretion. However, for any given transepithelial voltage there was significantly more potassium se-

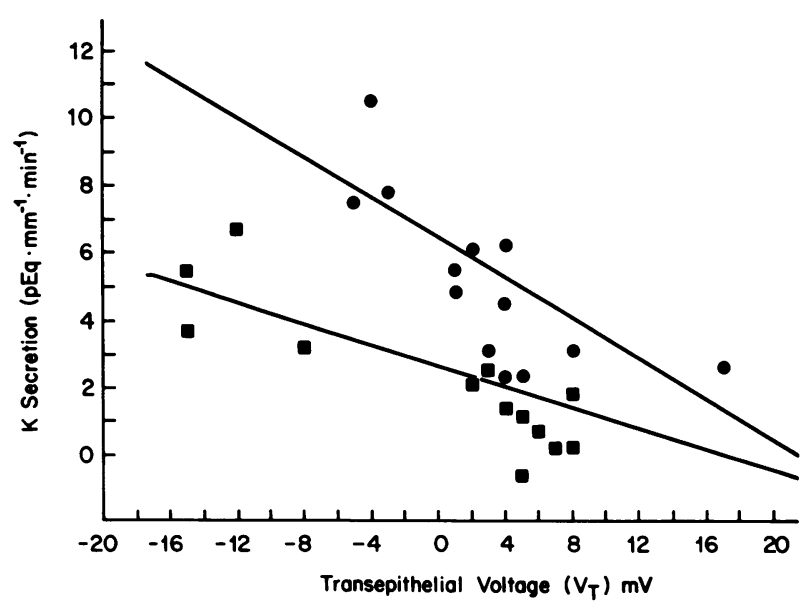

Figure 5 The relationship between transepithelial voltage and $\mathbf{K}$ secretion is plotted for cortical collecting tubules from adrenalectomized rabbits in protocol II. Data from low $K$ rabbits $\left(\mathrm{J}_{\mathrm{K}}=2.7-0.16 \mathrm{~V}_{\mathrm{T}}\right)$ are depicted by solid squares while data from high $\mathrm{K}$ rabbits $\left(\mathrm{J}_{\mathrm{K}}=6.3-0.32 \mathrm{~V}_{\mathrm{T}}\right)$ are depicted by solid circles. In tubules from rabbits on both diets there was a significant correlation between voltage and $K$ secretion. Each point represents the mean of three collections. In most tubules of each group two sets of three collections were taken: an early set (1-2 h after initiation of perfusion) and a late set (3-4 $\mathrm{h}$ after perfusion). 
cretion in the high potassium group than in the low potassium group. Thus the difference in potassium secretion between the two groups cannot be attributed to a difference in transepithelial voltage.

To examine other factors that may affect potassium secretion we plotted the relation between potassium secretion and sodium reabsorption (Fig. 6). There is a significant correlation of potassium secretion and sodium reabsorption. In this figure collection periods during measurement of lumen positive voltage are represented by closed symbols, whereas collections made during measurement of lumen negative voltage are represented by open symbols. It is of interest that the only significant overlap in net $\mathrm{K}$ secretion by these tubules occurred in those four instances (two tubules) where low $\mathrm{K}$ tubules exhibited significant lumen negative voltage.

\section{DISCUSSION}

To assess the mineralocorticoid requirement (or lack of it) in cortical collecting tubule adaptation to $\mathrm{K}$ loading, we elected to study tubules harvested from adrenalectomized rabbits. Our experiments add two fundamental observations to the existing knowledge concerning $\mathrm{K}$ adaptation in cortical collecting tubules: (a) The cortical collecting tubule, a well accepted target epithelium for aldosterone, demonstrates active secretion of $\mathrm{K}$ in the absence of mineralocorticoids; (b) This active $\mathrm{K}$ secretion responds appropriately to

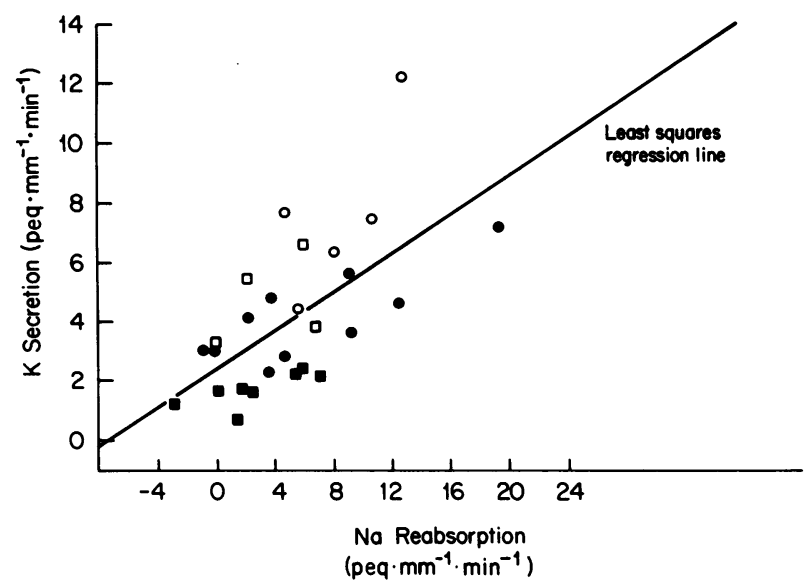

Figure 6 Net $\mathrm{K}$ secretion is plotted against net $\mathrm{Na}$ reabsorption in cortical collecting tubules from adrenalectomized rabbits in protocol II. Data from tubules from low $\left(\boldsymbol{\omega}, \mathbf{V}_{\mathbf{T}}\right.$ lumen positive; $\square V_{T}$ lumen negative) and high $K\left(0, V_{T}\right.$ lumen positive; $O, V_{T}$ lumen negative) diet groups are depicted. Open symbols refer to flux data when transepithelial voltage was lumen negative, while closed symbols refer to data obtained when transepithelial voltage was lumen positive. As in Fig. 5, each point represents the mean of three collections. $\mathrm{J}_{\mathrm{K}}=2.42+0.327 \mathrm{~J}_{\mathrm{Na}} \cdot r=0.61 . P<0.001$.
TABLE V

Comparison of Na and $\mathrm{K}$ Fluxes in Rabbit CCT from Various Studies

\begin{tabular}{|c|c|c|c|}
\hline Study & $\mathrm{J}_{\mathrm{Ne}}$ & $J_{k}$ & $\mathrm{~V}_{\mathrm{T}}$ \\
\hline & \multicolumn{2}{|c|}{$\mathrm{pmol} \cdot \mathrm{mm}^{-1} \cdot \min ^{-1}$} & $m V$ \\
\hline \multicolumn{4}{|l|}{ O'Neil and Helman (13) } \\
\hline Normal & 16.4 & -2.8 & -8.5 \\
\hline DOCA, 3-6 d & 23.6 & -6.6 & -12.4 \\
\hline DOCA, $11-18 \mathrm{~d}$ & 38.0 & -18.8 & -58.2 \\
\hline DOCA, 23-31 d & 29.2 & -23.9 & -29.2 \\
\hline \multicolumn{4}{|l|}{ Schwartz and Burg (12) } \\
\hline Normal & 34.2 & -13.8 & -16 \\
\hline DOCA, $10-15 \mathrm{~d}$ & 92.4 & -52.8 & -46 \\
\hline Low $\mathrm{Na}$ diet & 52.8 & -18.6 & -38 \\
\hline Low $\mathrm{K}$, high $\mathrm{Na}$ diet & 13.8 & -3.6 & -15 \\
\hline \multicolumn{4}{|l|}{ Fine et al. (24) } \\
\hline Normal diet & - & -7.6 & -13 \\
\hline High $\mathrm{K}$ diet & - & -19.6 & -29 \\
\hline \multicolumn{4}{|l|}{ Stokes et al. (14) } \\
\hline Normal & 23 & -15 & -20.8 \\
\hline DOCA, $1-6 \mathrm{~d}$ & 54 & -43 & -42.9 \\
\hline \multicolumn{4}{|l|}{ Present studies } \\
\hline \multicolumn{4}{|l|}{ Adx rabbits } \\
\hline High K diet & 6.2 & -5.3 & +2.1 \\
\hline Low $\mathrm{K}$ diet & 3.8 & -2.0 & +2.6 \\
\hline
\end{tabular}

dietary $\mathrm{K}$ intake. Our observation, that $\mathrm{K}$ secretion in cortical collecting tubules from adrenalectomized rabbits cannot be accounted for by the laws of simple ionic diffusion across single membranes, is not different from observations in tubules from animals with intact adrenals (15-17). We would like to stress, however, that our data does not exclude a role for mineralocorticoids in augmenting the potassium secretory capacity of the cortical collecting tubule in response to potassium loads. Indeed, maneuvers that increase endogenous mineralocorticoid chronically or the chronic administration of 11-deoxycorticosterone acetate (DOCA) result in augmented potassium secretion in the cortical collecting tubule perfused in vitro (12-14) and Table $\mathrm{V}$. Therefore, whether all or only part of the potassium secretory response to $\mathrm{K}$ loading occurs in the absence of mineralocorticoids will require further examination. It does appear, though, that potassium secretion over a considerable range can occur in the absence of mineralocorticoid. These findings correlate well with the clinical observation that severe hyperkalemia is rare in the Addisonian (3) and that potassium tolerance, at least for moderate potassium loads, is well preserved in adrenal insufficiency $(4,5)$.

Potassium transport in the cortical collecting tubule is believed to involve primarily transcellular move- 
ment. Stokes (17) has shown that there is a remarkably constant ratio of sodium reabsorption for potassium secretion in both normal and DOCA-treated rabbits. This relatively constant ratio of potassium secretion for sodium reabsorption has been interpreted as evidence for a sodium-potassium exchanger, requiring energy and presumably located at the basolateral membrane. A likely candidate for this exchanger is sodium-potassium activated adenosine triphosphatase, which has been shown to reside in the basolateral membranes and require adenosine triphosphate for the translocation of sodium and potassium. However, direct measurement of sodium potassium activated adenosine triphosphatase in cortical collecting tubules from adrenalectomized rabbits treated in an identical manner as those in protocol I of the present studies demonstrates low enzyme activity $(22,23)$. This observation is in keeping with the findings of Fine et al. (24) who demonstrated that the increased $\mathrm{K}^{+}$secretion of collecting tubules from $\mathrm{K}$-loaded normal or uremic rabbits was not associated with increased Na-K-ATPase activity. The apparent lack of a dependency of augmentation in cortical collecting duct $\mathrm{K}^{+}$secretion on increased $\mathrm{Na}-\mathrm{K}$-ATPase activity is in contrast with the findings of Doucet and Katz (25). We have no clear explanation for the different observations.

With respect to the differences in potassium secretion between the dietary groups in protocol II, two variables were measured in the same tubules in which potassium secretion was measured: transepithelial voltage and sodium reabsorption. As with protocol I there was a significant relation between potassium secretion and transepithelial voltage. However, because the high and low diet groups had mean transepithelial voltages that were not different, the difference in potassium secretion between the two groups could not be attributed to an effect of transepithelial voltage. Hence, as shown in Fig. 5, for a given value of transepithelial voltage, potassium secretion was greater in the high potassium group than in the low potassium group.

Analysis of the relation between sodium reabsorption and potassium secretion demonstrated a linear correlation of these two variables (Fig. 6). Comparison of sodium reabsorptive rates for both the high potassium and low potassium diet groups demonstrates a small but significant difference between the two groups (low potassium $=3.84 \pm 0.67 \mathrm{pmol} \mathrm{mm}^{-1} \mathrm{~min}^{-1}$ high potassium $=6.24 \pm 1.17 \mathrm{pmol} \mathrm{mm}^{-1} \min ^{-1} P$ $<0.05$ ). If one estimates the magnitude of potassium secretion that can be related to the differences in sodium reabsorption between tubules from the two dietary groups (by multiplying the difference in $\mathrm{Na}$ reabsorption between the low and high $\mathrm{K}$ diet groups by the slope of the line in Fig. $6,2.40 \mathrm{pmol} \cdot \mathrm{mm}^{-1} \cdot \mathrm{min}^{-1}$ $\times 0.327$ ), it is evident that differences in net sodium reabsorption can account for only a fraction $(0.78$ $\left.\mathrm{pmol} \cdot \mathrm{mm}^{-1} \cdot \mathrm{min}^{-1}\right)$ of the difference in observed net $\mathrm{K}$ secretion $\left(3.32 \mathrm{pmol} \cdot \mathrm{mm}^{-1} \cdot \mathrm{min}^{-1}\right)$. Thus, while a relation between sodium reabsorption and potassium secretion was demonstrable in these tubules, differences in net sodium reabsorption could not account for the differences in $\mathrm{K}$ secretion between the two dietary groups. Because differences in transepithelial voltage could also not account for the differences in observed $K$ secretion we conclude that the effect of dietary $K$ intake is mediated, at least in part, by other factor(s). The nature of these additional factors (intracellular $\mathbf{K}$ activity, alterations in luminal or peritubular membrane $K$ conductance, etc.) are not addressed by our studies.

These studies are the first to describe $\mathrm{Na}$ and $\mathrm{K}$ transport in cortical collecting tubules obtained from adrenalectomized rabbits. We compare (Table V) the results of our studies with $\mathrm{Na}$ and $\mathrm{K}$ fluxes in tubules from normal animals and animals in which mineralocorticoid levels were altered by diet or exogenous administration $(12-14,24)$. It is notable that adrenalectomy sharply reduces net $\mathrm{Na}$ reabsorption and lumen negative voltage in cortical collecting tubules perfused in vitro. We attribute the low values in the present studies to the fact that the rabbits from which our tubules were obtained had no detectable mineralocorticoid activity in their plasma for a minimum of $7 \mathrm{~d}$. In studies using dietary manipulations of salt intake of intact animals such prolonged and complete suppression of mineralocorticoid activity is difficult to achieve. In addition, it is also apparent that maneuvers that increase mineralocorticoid activity in the animals result in increased $\mathrm{Na}$ absorption, $\mathrm{K}$ secretion, and lumen negative voltage. Finally, it is interesting to note that in tubules from rabbits in which endogenous mineralocorticoid levels were suppressed by a low $K$, high $\mathrm{Na}$ diet (12) K secretion was slightly greater but close to the value seen in the low $K$ tubules of this study.

It should be remembered that all of our studies were carried out in tubules obtained from adrenalectomized but glucocorticoid-replaced animals. Because our major goal was to address the mineralocorticoid dependency of renal $\mathrm{K}$ adaptation, we elected to keep the glucocorticoid background intact and constant. In view of the observation of Rodriguez et al. (26), who found that whole cortical or medullary Na-K-ATPase activity was more responsive to a single dose of dexamethasone than aldosterone, we cannot exclude a permissive role for glucocorticoids in the renal adaptation to increased $\mathrm{K}$ intake.

In summary, this study provides evidence that the cortical collecting tubule of glucocorticoid-replaced adrenalectomized rabbits is capable of active potassium secretion and that the magnitude of potassium 
secretion responds to changes in dietary $\mathrm{K}$ intake. This effect is not wholly attributable to changes in sodium reabsorption or transepithelial voltage. Irrespective of the mechanism, these studies support the notion that the cortical collecting tubule can contribute to the $\mathrm{K}$ homeostasis of Addison's disease by responding to increased dietary $\mathrm{K}$ intake with increased $\mathrm{K}$ secretion.

\section{ACKNOWLEDGMENTS}

The authors appreciate the aid of Dr. William Campbell in performing the plasma steroid assays and Dr. Jon Blachley in performing the tissue $\mathrm{K}$ measurements. The technical support of Ms. Susan Corona, Ms. Sharon Bracey, and Ms. Alice Gung is also appreciated. Ms. Cathrine Schmid and Ms. Yvonne Wilborn prepared the manuscript.

These studies were supported by National Institutes of Health Research grants 5-R01-AM-23901-02 and 5-R01-AM1467-10. Dr. Wingo is the recipient of a National Kidney Foundation Fellowship Award and Dr. Jacobson is a recipient of National Institutes of Health Research Career Development Award 1-K04-AM-00537-03.

\section{REFERENCES}

1. Seldin, D. W., L. G. Welt, and J. H. Cort. 1956. The role of sodium salts and adrenal steroids in the production of hypokalemic alkalosis. Yale J. Biol. Med. 29: 229-247.

2. Relman, A. S., and W. B. Schwartz. 1952. The effect of DOCA on electrolyte balance in normal man and its relation to sodium intake. Yale J. Biol. Med. 24: 540558.

3. Fawley, F. F. 1967. Adrenal cortical insufficiency. In The Adrenal Cortex. A. B. Eisenstein, editor, Churchill Ltd., London. 439-522.

4. Talbott, J. H., L. J. Pecora, R. S. Melville, and W. V. Cansolayio. 1942. Renal function in patients with Addison's disease and in patients with adrenal insufficiency secondary to pituitary pan-hypofunction. J. Clin. Invest. 21: 107-119.

5. Cutler, H. H., M. H. Power, and R. M. Wilder. 1938. Concentrations of chloride sodium and potassium in urine and blood. JAMA (J. Am. Med. Assoc.). 111: 117122.

6. Hayslett, J. P. 1978. Potassium adaptation after reduction of nephron population. Yale J. Biol. Med. 51: 283288.

7. Malnic, G., R. M. Klose, and G. Giebisch. 1966. Micropuncture study of distal tubular potassium and sodium transport in rat nephron. Am. J. Physiol. 211: 529-547.

8. Stanton, B. A., D. Biemesderfer, J. B. Wade, and G. Giebisch. 1981. Structural and functional study of the rat distal nephron: Effects of potassium adaptation and depletion. Kidney Int. 19: 36-48.

9. Gross, J. B., M. Imai, and J. P. Kokko. 1975. A functional comparison of the cortical collecting tubule and the distal convoluted tubule. J. Clin. Invest. 55: 1284-1294.
10. Marver, D., and M. J. Schwartz. 1980. Identification of mineralocorticoid target sites in isolated rabbit cortical nephron. Proc. Natl. Acad. Sci. USA. 77: 3672-3676.

11. Garg, L. C., M. Knepper, and M. B. Burg. 1981. Mineralocorticoid effects on NaK ATPase in individual nephron segments. Am. J. Physiol. 240: F536-F544.

12. Schwartz, G. J., and M. B. Burg. 1978. Mineralocorticoid effects on cation transport by cortical collecting tubules in-vitro. Am. J. Physiol. 235: F576-F585.

13. O'Neil, R. G., and S. I. Helman. 1977. Transport characteristics of renal collecting tubules and influence of DOCA and diet. Am. J. Physiol. 233: F544-F558.

14. Stokes, J. B., M. J. Ingram, A. D. Williams, and D. Ingram. 1981. Heterogeneity of the rabbit collecting tubule: localization of mineralocorticoid hormone action to the cortical portion. Kidney Int . 20: 340-347.

15. Grantham, J. J., M. B. Burg, and J. Orloff. 1970. The nature of transtubular $\mathrm{Na}$ and $\mathrm{K}$ transport in isolated rabbit renal collecting tubules. J. Clin. Invest. 49: 18151826.

16. Stoner, L. C., M. B. Burg, and J. Orloff. 1974. Ion transport in cortical collecting tubule; effect of amiloride. Am. J. Physiol. 227: 453-459.

17. Stokes, J. B. 1981. Potassium secretion by cortical collecting tubule: relation to sodium absorption, luminal sodium concentration, and transepithelial voltage. Am. J. Physiol. 241: F395-F402.

18. Knochel, J. P., and E. M. Schlein. 1972. On the mechanism of rhabdomyolysis depletion. J. Clin. Invest. 51: $1750-1758$.

19. Burg, M. J., J. Grantham, M. Abramow, and J. Orloff. 1966. Preparation and study of fragments of single rabbit nephrons. Am. J. Physiol. 210: 1293-1298.

20. Schafer, J. A., S. L. Troutman, and T. E. Andreoli. 1974. Volume reabsorption, transepithelial potential differences, and ionic permeability properties in mammalian superficial proximal straight tubules. J. Gen. Physiol. 64: $582-607$.

21. Jacobson, H. R., and J. P. Kokko. 1975. Intrinsic differences in various segments of the proximal convoluted tubule. J. Clin. Invest. 57: 818-825.

22. Petty, K. J., J. P. Kokko, and D. Marver. 1981. Specific influence of aldosterone on $\mathrm{NaK}$ ATPase activity in the cortical collecting tubule. Clin. Res. 29: 473A. (Abstr.).

23. Petty, K. J., J. P. Kokko, and D. Marver. 1981. Secondary effect of aldosterone on NaK ATPase activity in the rabbit cortical collecting tubule. J. Clin. Invest. 68: 15141521 .

24. Fine, L. G., N. Yanagawa, R. G. Schultze, M. Tuck, and W. Trizna. 1979. Functional profile of the isolated uremic nephron. Potassium adaptation in the rabbit cortical collecting tubule. J. Clin. Invest. 64: 1033-1043.

25. Doucet, A., and A. I. Katz. 1980. Renal potassium adaptation: NaK ATPase activity along the nephron after chronic potassium loading. Am. J. Physiol. 238: F380386.

26. Rodriguez, H. J., S. K. Sinha, J. Starling, and S. Klahr. 1981. Regulation of renal NaK ATPase in the rat by adrenal steroids. Am. J. Physiol. 241: F186-F195. 